\section{Resumen}

A partir de tres autores claves para el pensamiento occidental, este artículo muestra las crisis y aporías de la pedagogía en la sociedad moderna. Con Herbart se define una concepción del ser humano como ente formable y, por tanto, necesitado de educación. Con Kant se evidencia el problema de legitimación de la educación bajo el presupuesto de un sujeto libre que se autodetermina. Con Rousseau se plantea el asunto de legitimar la educación y sus fines en relación con una concepción teleológica de la perfectibilidad (perfectibilité) y con una concepción del niño como otredad natural indeterminada. Se muestra cómo, bajo las coordenadas modernas, surge una concepción de lo humano que al ponerse en relación con la praxis y el pensamiento pedagógico muestra aspectos contradictorios y aporéticos que siguen marcando a la pedagogía en la actualidad y que es necesario problematizar desde perspectivas no afirmativas.

\section{Palabras Claves}

Formabilidad, perfectibilidad, animalidad, pedagogía, antropología pedagógica, formación, educación, Kant, Rousseau, Herbart.

\section{Abstract}

This article shows the crisis and pedagogical doubts in modern society from the perspectives of three key authors of the Western thought. Herbart defines a conception of the human being as formable and therefore, in need of education. According to Kant the problem of legitimization in basic education is evident and the premise of a liberal subject depends on the individual. However, Rousseau explains the importance of legitimizing education and its porpoises in relation to the teleological conception of perfectibility (perfectibilité) and the concept of the child as naturally undetermined as well. His perspective also shows how a new conception of the human being emerges under the modern coordinates and how it is related to praxis and pedagogical thought in order to highlight contradictory and aporetic aspects that presently exist in pedagogy and which are necessary to examine disaffirmed perspectives.

\section{Keywords}

Formability, perfectibility, animality, pedagogy, pedagogical anthropology, training, education, Kant, Rousseau, Herbart. 


\title{
Crisis y aporías de la educación en la sociedad moderna occidental: elementos iniciales para un debate antropológico-pedagógico sobre educación y posmodernidad ${ }^{1}$
}

\author{
Andrés Klaus Runge Peña \\ Diego Alejandro Muñoz Gaviria ${ }^{3}$
}

“ ¿Quién puede definir la dirección de una biografía humana o de la historia entera?; pasmo, pues, ante lo que sea indefectiblemente el hombre. Tal perplejidad antropológica pide ayuda a la pedagogía. El ente humano queda percibido como esencia inesencial, como tarea. La suma de datos se muestra flaca en vistas a entregar el hombre. El cómo, el qué y el quién sea el anthropos es doctrina que no le viene dada a este, sino que constituye su quehacer primario. El hombre pasa a ser animal crísico. Esta palabra hay que entenderla desde su etimología griega: crisis, en griego clásico, significa decisión; provenía del verbo krino, "yo decido". Al hombre le incumbe tener que decidirse, y aquí interviene ya el proceso educador. Este pende de la decisión antropológica. Sin antropología no resulta factible la pedagogía". Octavi Fullat, 1997, p. 22

\footnotetext{
1 Este escrito forma parte de los resultados del proyecto interuniversitario: "Paradigmas y Conceptos en Educación y Pedagogía", financiado por COLCIENCIAS (PRE00439015542), en el que participa el Grupo de Investigación sobre Formación y Antropología Pedagógica e Histórica —FormaF- de la Universidad de Antioquia. Texto recibido el 13 de septiembre del 2010, evaluado el 1 de noviembre del 2010 y arbitrado 20 de diciembre del 2010.

${ }^{2}$ Licenciado en Educación: Inglés-Español de la Universidad de Antioquia, Doctor en Ciencia de la Educación de la Universidad Libre de Berlín, Profesor de Pedagogía y Antropología Pedagógica de la U. de A. y Coordinador del Grupo de Investigación sobre Formación y Antropología Pedagógica e Histórica —FormaF-. E-Mail: aklaus@ayura.udea.edu.co

${ }^{3}$ Sociólogo, Especialista en Contextualización Psicosocial del Crimen, Magíster en Psicología de la Universidad de San Buenaventura Medellín, Estudiante del Doctorado en Ciencias Sociales: Niñez y Juventud de la Universidad de Manizales y el CINDE. Director del Grupo Interdisciplinario de Estudios Pedagógicos de la Universidad de San Buenaventura, y miembro del Grupo sobre Formación y Antropología Pedagógica —FormaF- de la Universidad de Antioquia. E-Mail: diegomudante@hotmail.com
} 


\section{Introducción}

En la contemporaneidad, el devenir de la sociedad moderna occidental, de aquella configurada más o menos en el siglo XVII en Europa y que en la actualidad asume un matiz mundial, se encuentra sumergida en lo que autores como Habermas (2000) y Beck (1998) han enunciado como la crisis social. Esta crisis se puede reconocer como la materialización del agotamiento de las energías utópicas o como la objetivación de una sociedad signada por el riesgo y por el desencanto frente a ciertas promesas no cumplidas. La crisis, en ese sentido, se puede comprender a partir de una doble caracterización: como un conjunto de aporías " "internas” y como un conjunto de contingencias 5 "externas". La crisis como grupo de aporías “internas" se refiere a la incapacidad de autosostenimiento, autoconservación y autopoiesis ${ }^{6}$ de la misma sociedad moderna occidental, debido al descrédito expandido con respecto a sus confianzas básicas representadas en grandes creencias como el progreso, la industrialización, la democracia, entre otras. Estas aporías enuncian, entonces, la falta de poros o de alternativas utópicas, es decir, de proyectos sociales capaces de fusionar ideales futuristas con realidades históricas concretas. Las sin salidas que tales aporías producen, generan así una sensación de agotamiento y desasosiego, y, además, proyectan en los mundos de la vida cierta situación de vulnerabilidad de cara a las amenazas de un contexto contingente y azaroso (Adorno, 1975, Beck, 1998).

De otro lado, la crisis como grupo de contingencias "externas" hace alusión a la incapacidad de las formaciones sociales modernas de comprender y enfrentar con energías utópicas, tanto los fenómenos socioambientales y culturales que dan la sensación de que lo existente puede ser de otra forma, como la manifestación de las consecuencias perversas de las acciones orientadas por las grandes creencias modernas; por ejemplo, como la del progreso, proceso civilizatorio, la industrialización, la democracia, la política, entre otras. Acá el riesgo se convierte en la expresión concreta de este tipo de crisis y, en su sentido más técnico, puede comprenderse como la sumatoria de la vulnerabilidad interna de la sociedad moderna, además de las amenazas externas devenidas del ecosistema transformado y de otras propuestas civilizatorias (Beck,1998).

En la perspectiva anterior, la sociedad actual puede definirse como sociedad en crisis, en proceso de confrontación consigo misma y con sus correlatos o consecuencias (modernidad reflexiva). La idea en este sentido, será la reivindicación de una postura autocrítica actual que sea capaz de significar dichas crisis como oportuni-

\footnotetext{
${ }^{4}$ Se entiende por aporías la emergencia de situaciones o condiciones existenciales donde aparentemente se cierran las opciones u oportunidades.

${ }^{5}$ Para Wulf la contingencia es la posibilidad de pensar y expresar las cosas de formas diferentes, bajo la idea de que todo puede ser posible de una u otra manera. Cf.: Wulf, 2004.

${ }^{6}$ Se entiende la auto-poiesis como la capacidad que tienen los sistemas de auto-producirse, es decir, de generar procesos de configuración internos (Luhmann, 1991).
} 
dad de cambio, como posibilidad de decisión, y no como desesperanza, vacuidad o desasosiego. Con esta idea se propone una mirada a la crisis moderna con respecto a lo educativo. Lo que planteamos es que la configuración de la praxis educativa —educación - en la Modernidad ${ }^{7}$ se da a partir de unos nuevos presupuestos antropológico-pedagógicos con los que se pone en evidencia, a su vez, su carácter antinómico y antitético. En la medida en que dicha contrariedad todavía pervive en la praxis y el pensamiento pedagógico contemporáneo y en la medida en que dichos principios gozan de común aceptación por la mayoría de los miembros del campo pedagógico, es necesario que estos se vuelvan objeto de análisis y reflexión por parte del pensamiento pedagógico — de la pedagogía- en el marco de una modernidad reflexiva o posmodernidad en crisis. Planteadas entonces las antinomias y situaciones contradictorias, se trata de mostrar la importancia y necesidad actual de un pensamiento pedagógico que considere sus propios principios y fundamentos en una época de crisis. Dentro de las antinomias en la configuración de la praxis educativa moderna que ha de pensar la pedagogía están: ser y norma, sujeto y objeto, libertad y coacción, naturaleza y cultura, presente y futuro. Las contrariedades que evidencian estos pares tienen que ver, fundamentalmente, con una concepción predominante del ser humano en la modernidad en la que, para nuestra temática en particular y como veremos, Jean-Jacques Rousseau, Johann Friedrich Herbart e Immanuel Kant cumplieron un papel destacable y rerpesentativo.

\section{La crisis como problema de la reflexión pedagógica}

Las crisis y aporías como problemas pedagógicos permiten recuperar la relación dialéctica existente entre anthropos y paideia, entre ideales del ser humano y sus formas de engendrarse socialmente, entre fines educativos y agencias formativas, entre teoría y praxis. Lo pedagógico se configura en esta narración, entonces, como la

\footnotetext{
${ }^{7}$ Acá nos adherimos a la concepción de modernidad que plantea Ulrich Beck. "Con el concepto de sociedad de riesgo Beck se sitúa en la mitad del debate entre modernidad y posmodernidad. Para este autor el desarrollo de la moderna sociedad industrial se ha de pensar desde dos perspectivas: de un lado, en sus inicios, como sociedad industrial, en la que se llevan a cabo procesos de modernización simple que consisten, en términos generales, en dinámicas de desencantamiento del mundo tal y como lo propuso Weber, con base en las cuales se pretendía desmontar el cobijo simbólico de la tradición premoderna para instaurar la legitimidad del nuevo orden moderno con sus propias señales simbólicas. De otro lado, en la contemporaneidad se puede pensar la sociedad industrial en la época actual como sociedad del riesgo. Como se puede notar, no se trata de una nueva época, sino de un modo de desenlace de la modernidad. En la sociedad del riesgo los procesos de modernización ya no caen necesariamente en las credulidades iniciales de la modernización simple y se orientan por el desencantamiento frente a este proceso. Se trata entonces de un desencanto frente a la sociedad industrial, lo cual podría también enunciarse en términos de Giddens como un proceso de modernización reflexiva, es decir, una segunda modernización que antropologiza, cuestiona y problematiza las representaciones colectivas de la modernidad operando, para ello, con el referente moderno de la reflexividad del sujeto, esto es, con su capacidad de juicio y de decisión" (Runge Peña y Muñoz Gaviria, 2006, p. 35-36).
} 
pregunta reflexiva sobre la formación y educación de los sujetos, como la pregunta por los procesos de subjetivación que permiten una determinada manera de ser lo que se es (Fullat, 1997) en contextos postmodernos de crisis. En este sentido, lo pedagógico mismo deviene en crisis cuando los fines educativos modernos, universales y ahistóricos ya no son sustentables como tales en el campo disciplinar y profesional de la pedagogía, cuando la idea de perfectibilidad humana entra en crisis, se deshace, se vuelve líquida, cuando la praxis educativa pierde legitimidad y justificación desde un punto de vista pedagógico. En este contexto, la reflexión pedagógica podría girar en torno a la pregunta por unos tipos de formación y de educación no afirmativos, por ideas internas y externas de subjetivación que apuesten por concepciones humanas no dogmáticas ni normativas. El ser humano sería el fruto de sus aperturas al mundo, no de sus formas de clausura y distanciamiento (Benner, 1998).

Así pues, las contrariedades que evidencian estos pares tienen que ver fundamentalmente con una concepción predominante del ser humano en la modernidad en la que, para nuestra temática en particular, Jean-Jacques Rousseau, Johann Friedrich Herbart e Immanuel Kant resultan ejemplares. Esto encuentra su presupuesto fundamental en la formabilidad (Bildsamkeit) humana. Recordemos que cuando, desde un punto de vista histórico-pedagógico y antropológico-pedagógico, se alude a la formabilidad humana, inmediatamente hay que hacer referencia al trabajo de Johann Friedrich Herbart. Al comienzo de su Umriss pädagogischer Vorlesungen (Esbozo de lecciones pedagógicas) — libro traducido al español por Lorenzo Luzuriaga y aparecido en Madrid (España), en 1935 con el título: "Bosquejo para un curso de pedagogía”-, en el numeral uno de la introducción Herbart escribe lo siguiente: "El concepto fundamental de la pedagogía es la formabilidad ${ }^{8}$ del alumno. Anotación:

\footnotetext{
${ }^{8}$ Si bien el término "Bildsamkeit" no tiene un equivalente exacto en el español, creemos, no obstante, que el concepto utilizado por Luzuriaga se presta para confusiones en nuestra lengua y, además, pasa por encima de toda una tradición pedagógica que, precisamente con el uso matizado de conceptos como este, ha tratado de construir un discurso propio. Acá me refiero a las teorías clásicas de la formación, a las teorías de la formación en la actualidad y a muchos de los planteamientos que se inscriben dentro de una antropología pedagógica, en donde no solo se trabaja con base en una diferencia conceptual entre "educación" y "formación", sino que se plantea la "formabilidad" como un principio antropológico (Roth) y pedagógico (Benner) fundamental. Es importante señalar que el término "Bildsamkeit" proviene de la palabra "Bild" que significa en alemán imagen, retrato, pintura, ilustración, idea. Existe también el verbo "bilden", derivado de acá, que significa formar, dar forma. La partícula "-sam" adjetiva este verbo. El resultado es la palabra "Bildsam", cuyo equivalente en español sería la palabra "formable". En la palabra "Bildsamkeit" la terminación "-keit" sustantiva nuevamente dicho adjetivo. Así pues, una operación similar en el español que estuviera en concordancia con el proceso llevado a cabo en la lengua alemana nos llevaría al término "formabilidad". Sabemos que la expresión "traductore traidore" nos toca a todos; por eso, independientemente de las discusiones que puedan surgir en torno al posible uso o no de este neologismo, lo que sí nos parece claro —y es lo que se quiere señalar acá- es que el término usado en español, a saber: el de educabilidad, es bastante desacertado. Visto etimológicamente, por ejemplo, el término educabilidad supondría un parentesco con la palabra "educable", y esta, a su vez, con "educar". El término "educar" proviene del latín "educere" y con él se hace referencia a un proceso en el que un
} 
el concepto de formabilidad tiene un alcance más vasto. Este se extiende incluso a los elementos de la materia. Conforme a la experiencia, se le puede seguir hasta en aquellos elementos que intervienen en el metabolismo de los cuerpos orgánicos. De la formabilidad de la voluntad hay rastros en las almas de los animales más nobles. Pero la formabilidad de la voluntad para la moralidad solo la conocemos en los seres humanos" (Herbart, 1984, p. 5) ${ }^{9}$. Gracias a Herbart, este concepto se convirtió en uno de los conceptos principales de la pedagogía y de la antropología pedagógica y adquiere un carácter antropológico particular, entendido como "formabilidad de la voluntad para la moralidad".

De la condición formable del ser humano resulta también la "necesidad de ser educado" (Erziehungsbedürftigkeit); sin embargo, el concepto de formabilidad no se puede definir en términos de un contenido. Tampoco hace referencia a algo innato. De ahí que deba entenderse, más bien, como un principio, como un concepto operativo, cuyas posibles comprensiones siempre van a estar supeditadas a situaciones concretas y a contextos específicos. Como bien lo había visto Flitner en su "Pedagogía General", la formabilidad no se da por sí misma, sino donde se fomenta. Eso significa que se actualiza mediante acciones educativas. Pero veamos con mayor detalle los asuntos anteriormente mencionados que parten del presupuesto de la formabilidad humana y que evidencian esa situación crítica y aporética del pensamiento pedagógico moderno.

\subsection{Aporía y crisis de la educación con el reconocimiento de la infancia}

Jean-Jacques Rousseau comienza la primera parte de su Emilio o de la educación cuestionando la visión despectiva de sus contemporáneos con respecto a la infancia; visión enraizada profundamente en la tradición cristiana y según la cual el niño era concebido como un ser humano incompleto, un ser a medias, una carga pesada, un mal necesario y hasta un pervertido. En contraposición a esto Rousseau dice: “iSuelen quejarse del estado de la infancia! No comprenden que la raza humana habría perecido si el hombre no hubiera empezado por ser niño" (O. C., T. IV, p. 246-247; 1998, p. 38). La importancia de Rousseau en este sentido radica en que rompe con

A influye (induce) sobre un B. Es decir, que educar — como enseñar- designa ante todo una acción que proviene de un exterior, aspecto este que riñe con el concepto de formación como despliegue y devenir algo otro a partir de sí y, por supuesto, en contacto con el mundo.

9 "Der Grundbegriff der Pädagogik ist die Bildsamkeit des Zöglings. Anmerkung. Der Begriff der Bildsamkeit hat einen viel weiteren Umfang. Er erstreckt sich sogar auf die Elemente der Materie. Erfahrungsmäßig läßt er sich verfolgen bis denjenigen Elementen, die in den Stoffwechsel der organischer Leiber eingehen. Von der Bildsamkeit des Willens zeigen sich Spuren in den Seelen der edleren Tiere. Aber Bildsamkeit des Willens zur Sittlichkeit kennen wir nur beim Menschen" (Herbart, 1984, p. 5). La traducción al español es nuestra. 
una tradición de pensamiento en la que se concebía la infancia como un estado de perversión y de maldad. Así, se comienza a reconocer entonces, por primera vez, el modo de ser niño como un estado con una dignidad y derecho propio.

Lo importante para resaltar acá es que el niño, en tanto ser humano en pleno desarrollo, es un ser perfectible por excelencia que posee incontables posibilidades de autorrealización y de autoformación. De allí que el reconocimiento de la niñez y de sus propios derechos signifique reconocer, por tanto, su derecho a la libertad y al perfeccionamiento. Si el ser humano está ahora arrojado en el mundo y es responsable de su libertad, entonces el niño, en tanto ser humano, debe gozar también de una libertad similar. Con el reconocimiento rousseauniano de la niñez ${ }^{10}$ como un modo de ser propio y con el reconocimiento de sus derechos, se deja, o mejor, se pone al niño en situación de libertad $^{11}$. Entre perfectibilidad, voluntad y libertad se establece un vínculo fundamental, con lo que resulta una idea de perfectibilidad como capacidad, potencialidad y libertad de perfeccionarse ${ }^{12}$. Además, aquellas, en contacto con la imaginación, hacen que el ser humano deje de ser un ser instintivo y se convierta en un ser social que aspira a extender su ser.

Podríamos decir entonces que uno de los grandes aportes de Rousseau consiste en antropologizar la perfectibilidad humana, o mejor, en plantearla como una condición antropológica ${ }^{13}$. La perfectibilidad, junto con la sociabilidad y la libertad, se

\footnotetext{
${ }^{10}$ Cf.: Runge, 1999.

${ }^{11}$ En este orden de ideas, lo primero que se vuelve objeto de crítica en el Emilio es el uso de las fajas, y de allí que se elogie, por otro lado, el amamantamiento (la maternidad). Para una crítica y relativización del "amor maternal" entendido como un comportamiento social e histórico producto de la Burguesía y de las influencias de discursos como los de Rousseau, se puede consultar: Badinter, 1980.

12 Vista así, la perfectibilidad no queda restringida únicamente a un desarrollo psicológico o al despliegue de las capacidades racionales y lingüísticas, sino que aparece como una determinación antropológica más fundamental que comprende al ser humano en su totalidad; y esto significa entonces que no solo el espíritu, sino también otros aspectos ligados a la corporalidad entran a jugar en ello un papel determinante. El ser humano moderno queda puesto entre los límites del "perfeccionamiento" e "inmejorabilidad" (Kamper y Wulf, 1994) humanos.

13 Planteamientos psicológicos como los de Piaget, Kohlberg, entre otros, y pedagógicos como los de Montessori, al centrar su atención solo en la génesis y desarrollo "natural" del ser humano desde un perspectiva cognitiva reducen con ello la perfectibilidad a estados o contenidos supuestamente universales. Esto ha provocado, entre otras cosas, que la visión de la formación se reduzca a formación técnica o funcional, y la perfectibilidad a una ideología de progreso discriminatoria. El desarrollo se convierte así en algo pronosticable que corresponde a un plan organizado, previsto y controlado. De allí entonces que se seleccionen determinados procesos de desarrollo y no otros. Hay que tener en cuenta, no obstante, que antes que un desarrollo natural, lo que Rousseau antepone con mayor fuerza es la capacidad del ser humano para perfeccionarse: la perfectibilité. Rousseau no determina la perfectibilidad de un modo positivo, en ese sentido no es ni teleológica, ni normativa: la perfectibilidad puede llevar al ser humano a la perfección, pero también a la depravación. La perfectibilidad es, además, la facultad que permite el desarrollo ontogenético del ser humano. En este sentido, desde el mismo Rousseau los discursos sobre el desarrollo "natural" necesitan ser relativizados y contextualizados histórica y socialmente, y la formación no debe quedar reducida a una serie de etapas o estados prescritos.
} 
constituyen en las cualidades específicas que distinguen al ser humano del animal. Rousseau sostiene al respecto: "Pero aun cuando las dificultades que rodean todas estas cuestiones dejaran pie para disputar sobre esta diferencia del hombre y del animal, hay otra cualidad muy específica que los distingue sobre la que no puede haber réplica: es la facultad de perfeccionarse; facultad que, con la ayuda de las circunstancias, desarrolla sucesivamente todas las demás, y reside en nosotros tanto en la especie como en el individuo, mientras que un animal, al cabo de algunos meses es lo que será toda su vida, y su especie, al cabo de mil años, lo que era el primero de esos mil años“ (Rousseau, O. C., T. III, p. 142; 1980, p. 220).

Determinado ahora por la libertad y perfectibilidad, el desarrollo humano no es más para Rousseau un "telos" en el sentido aristotélico y tampoco un proceso de formación como proceso de asemejarse a Dios. Gracias a la condición inherente de poderse perfeccionar el ser humano se sale de la creación, de un "desarrollo natural", y empieza a hacer de sí su propia historia. Visto así, el ser humano no aparece más como un ser condicionado por su desarrollo y deviene en proyecto humano. Desde el punto de vista de Rousseau el perfeccionamiento humano no se puede concebir como una teleología o como un progreso causal condicionado ${ }^{14}$.

Si en palabras de Herbart el ser humano es un ser formable, y en palabras de Kant un ser que hace de sí su propio plan de comportamiento, para Rousseau, de igual manera, este es también un ser perfectible. El ser humano es concebido como un ser arrojado en el mundo y responsable de su libertad; por ello, el niño como ser humano debe gozar también de una libertad similar. Rousseau es el primero que, a partir de una diferenciación radical con el adulto, enfatiza en el modo de ser otro de la infancia. Como lo dice Wimmer: "hay que agradecerle a Rousseau el haber tenido el conocimiento de que el niño en tanto otro entra en el campo de observación de la pedagogía, pero no como un adulto deficiente, es decir, parecido a este último, solo que incompleto y, por ello, subordinado a aquel; sino que, en tanto niño, como un ser perfecto a su propio modo" (Wimmer, 1994, p. 120).

\footnotetext{
${ }^{14}$ No hay que desconocer que, según Rousseau, el ser humano pasa inevitablemente por un proceso de perfeccionamiento que implica, a la vez, la posibilidad de perfección como de corrupción. Rousseau no determina la perfectibilidad de un modo positivo y, en ese sentido, esta no es teleológica. Es precisamente en este contexto que la naturaleza del ser humano no puede ser vista más como algo bueno o malo — como lo planteaba de alguna manera Hobbes-, ya que malas o buenas pueden ser únicamente las realizaciones de dicha perfectibilidad. Más bien se trata de que al ser humano, en tanto ser libre y perfectible, le es "natural" la "desnaturalización" o "renaturalización" (Derrida). De allí que ya no sea posible, ni se prefiera un "retorno a lo natural" — como se malinterpretó a Rousseau desde el mismo VoltaireLa naturaleza tan solo puede cumplir el papel de referente hipotético del que no sabe nada con certeza, pero que sirve para el ejercicio de crítica al presente. De todas maneras, en el programa pedagógico de Rousseau — por ejemplo, en el Emilio o de la educación - la historia "abierta" del ser humano va transformándose en una teleología de la armonía como aspiración humana a un estado de felicidad. El ser humano debe volver a encontrar entonces su puesto en la creación. Cf.: Zirfas, 1993.
} 
La niñez como otredad, como extraño, hace imposible sustentar cualquier concepción de la educación a partir o en una experiencia de la realidad sin falsear con ello la naturaleza no conocida del niño. Lo que quiere decir que con base en esa radical otredad del niño, se deslegitima toda forma de pensamiento pedagógico normativo, pues ese niño como naturaleza indeterminada, que de un modo proyectivo entraba en el horizonte de comprensión del adulto y así quedaba igualmente ligado a las apuestas de intervención de este último — de la pedagogía—, ahora, bajo estos parámetros, solo puede ser lo que es de conformidad ${ }^{15}$ con su propia naturaleza; en ese sentido, el niño debe buscar y lograr su determinación a partir de sí mismo. ¿Qué educación podría ser pensable bajo estas condiciones? ¿Qué tipo de educación sería posible que no traicione la naturaleza del niño y que no lo ate a una norma externa? ¿Qué tipo de educación que no arriesgue el "futuro de la naturaleza humana” (Habermas) y que no termine por convertirse en un ejercicio de dominación de dicha naturaleza?

Lo interesante es que no solo la educación en ese sentido no puede partir de algo dado porque el niño se le aparece como homo absconditus, sino que toda acción educativa, igualmente, se ve cómo una acción potencialmente abusiva. La pedagogía supuso encontrar la solución a esta situación con la ayuda de la psicología, especialmente durante la primera mitad del siglo XX, con la idea de que el niño debía adaptarse a sus propias normas ya no a partir de un saber externo a él, sino de un saber que partía de él mismo — del conocimiento respecto a su libre espontaneidad, del conocimiento de su naturaleza-. Sin embargo, esta humanización de la pedagogía, que se veía a sí misma a favor del niño y a partir del niño, y que se manifestaba en contra de toda forma de poder externo en la educación, no demoró en mostrarse también, con la ayuda, por ejemplo, de la psicología, como el intento de la total identificación y ocupación de la otredad del niño, como el intento de empoderarse teóricamente de su otredad para así poder disponer mejor de él ${ }^{16}$. Lo que a diferencia de un pensamiento y acción pedagógicos autoritarios se presentó como el nuevo gesto pedagógico amigable, a saber: la comprensión pedagógica del niño a partir de la asunción de la propia perspectiva de este último, terminó revelándose como una intención imperial por la ocupación del otro, de su lugar, precisamente con el propósito de lograr un control sobre él.

Rousseau desarrolla una teoría de la educación que, basada en un concepto de infancia como indeterminabilidad natural que le permite ser algo otro, rompe con toda imagen y determinación que se haga de ella por parte del adulto. El descubrimiento de la infancia, o mejor, de la otredad infantil se convierte por ello en

\footnotetext{
${ }_{15}$ Rousseau expresa que la naturaleza funge como un supuesto del que no podemos saber nada y que sirve como hipótesis para hablar de nuestro estado actual. De allí que utilice expresiones como "de conformidad con la naturaleza" y no se refiera a una naturaleza como tal, sino a una conjetura hecha desde cualquier situación actual.

${ }^{16}$ Cf.: Wimmer, 1994, p. 121.
} 
un presupuesto paradójico, pues además de reconocerla, sirve para ver la educación - positiva- como un ejercicio de coacción que no le hace derecho a esa otredad infantil, bien sea porque la niegue, la invisibilice o la destruya.

Ahora bien, todo esto puesto en relación con la educación significa lo siguiente: el ser humano como ser perfectible y abierto, en el sentido de Rousseau, oscurece toda esperanza de una educación perfecta y última. Hay un autoimpedimento del pensamiento pedagógico que viene dado en el hecho de que ya no puede legitimar la actividad educativa y las técnicas de su realización con base en una idea última - como la autonomía o la humanitas kantianas - relacionada con un deber ser, ya que la perfectibilidad tendría múltiples y variadas formas de realización con lo que, en consecuencia, se deslegitimaría toda educación referida normativamente a un único modo de ser. En Rousseau la indeterminabilidad de la naturaleza humana como punto clave de su reflexión escapa a toda posible anticipación.

Así, el discurso pedagógico de la modernidad establece una relación de tensión con las utopías, por un lado, porque las imágenes de ser humano que aquel proyecta - los fines educativos - tienen que ser vistas de un modo contingente desde el punto de vista histórico y cultural, y, por el otro, porque ya ninguna teleología puede concebir y comprender la determinación y destino humano. A ello se le suma también el hecho de que la forma concreta de la formación en tanto autoderminación individual, no se puede anticipar sin, al mismo tiempo, desmentirla o ponerla en entredicho. Ahora, como lo sostiene Benner: "la sociedad moderna se distingue de la premoderna precisamente en que el destino de los jóvenes, y con él su futura profesión, no solo les es desconocido a ellos mismos, por lo menos en un principio, sino también a sus personas de referencia adultas, educadores y maestros. En las condiciones de la sociedad moderna, querer saber tan temprano cuál será el destino de los niños es incompatible, no solo con lo que podemos prever con cierta verosimilitud pragmática, sino también con el derecho fundamental a la educación y a la autodeterminación” (Benner, 1998, p. 65). De allí entonces que el futuro se deba tratar como algo abierto, por lo que toda determinación del futuro posible del niño o del joven se muestra como contrario a lo que sería una correcta comprensión del niño y del joven como personas libres a las que habría que incitar para que construyan su propio futuro.

En ese sentido y por su parte, la pedagogía se ve avocada a reconocer que no sabe ni podrá saber quién es ese —el niño—a quien educa y mucho menos anticipar con certeza qué será. Es precisamente en ese marco de reflexión que "la pedagogía resultó ser ambivalente y contradictoria en sí misma. Por un lado, el desarrollo de la nueva pedagogía solo fue posible a partir del desmoronamiento de las concepciones y estructuras teleológicas provocado por la Ilustración. Por otro lado, sin embargo, la idea de la Ilustración de liberar la acción y el pensamiento del ser humano de los condicionamientos tradicionales, para fundamentarlos exclusivamente en la autonomía legisladora de la razón humanas, no se podía aplicar de igual modo a 
la naturaleza no humana que al ser humano en cuanto ser capaz de aprender y de desarrollarse a sí mismo, actuando discursiva e interactivamente. Si la concepción del ser humano tenía que ser congruente con la de su razón autónoma, de ningún modo se la podía deducir de un orden normativo teleológico predeterminado según el modelo de explicación mecánica de la naturaleza” (Benner, 1998, p. 14).

\subsection{La paradoja de la búsqueda de la perfección como meta a partir la intervención educativa como acción imperfecta}

De otro lado, a pesar del optimismo mayoritario frente a la educación, otra de las grandes paradojas no demora en salir a la luz cuando se cuestiona el hecho de que una actividad todavía imperfecta ${ }^{17}$ como la actividad educativa, se proponga precisamente como una estrategia de perfeccionamiento ${ }^{18}$. ¿Cómo puede perfeccionar o llevar a la perfección algo que no es perfecto? Como lo dice Oelkers: "Este hallazgo empírico —que la educación permanece como un fragmento- tiene que ser confrontado con el poder sugestivo de la visión de perfección. Esta superpone la duda frente a la posibilidad de contribuir precisamente con la formación elevada del ser humano contando con las debilidades de la educación. La debilidad es compensada mediante la fuerza de la meta deseada que juega con la redención. De un ser humano mejor se deriva la necesidad y la bondad de su educación. La educación misma permanece indeterminada en gran parte. La reflexión tiene su punto central en la meta, no en la posibilidad de alcanzarla. Pero, efectivamente, las fantasías de perfección dominan los discursos educativos desde los comienzos del platonismo; estas se constituyen en esperanzas pedagógicas liberadas de las oportunidades e impedimentos de sus contextos específicos" (Oelkers, 1997, p. 14). La tarea que se presenta es: no sacrificar el presente en nombre del futuro, no sacrificar el presente por el futuro; como tampoco reducir el futuro al presente.

Cualquiera que sea el caso siempre se trata de un perfeccionamiento que parte de la elaboración de la diferencia y de una exclusión de la contingencia, y que además presupone el progreso como un movimiento uniforme del individuo y/o la sociedad hacia un estado óptimo. De allí que las situaciones se tornen problemáticas y los programas de perfeccionamiento - bien sea que se planteen en términos evolutivos, acumulativos o adaptativos- se conviertan, en la mayoría de los casos, en las tiranías que se ejercen en nombre de un mejoramiento y humanización del mundo. En la modernidad ha resultado así una concepción antropológica fundada en una visión universal de ser humano que contiene, por lo general, el programa y

\footnotetext{
17 Imperfecta debido a su déficit tecnológico, a su reconocimiento de la incognoscibilidad total del niño, a su aceptación del carácter formable y, por tanto, contingente y abierto de este último, y a su visión insuficiente del futuro.
}

${ }^{18}$ Cf.: Oelkers, 1997, p. 13. 
las normas para su perfeccionamiento ${ }^{19}$. La pedagogía, por su parte, embriagada ahora por un optimismo que no ve más en el pasado una limitación y que asume el futuro como algo abierto, como un reto, desarrolla las maneras, formas y estrategias para que ese "es" llegue a su realización. De allí que la educación — la praxis educativa- adquiera, a pesar de su falta de concreción — de su déficit tecnológico, diría Luhmann (1996) - una incuestionada justificación, un valor de suma importancia y se constituya así en una de las estrategias, junto con el trabajo, más importantes en esa lucha contra la animalidad y contra la posibilidad de inmejorabilidad humana. La antropología moderna dice lo que el ser humano "es"; pero se trata de un "es" que pasa muy sutilmente a tomar la forma de un "deber ser" y en ello entra a ayudar la pedagogía con sus ideales de formación y de perfeccionamiento.

Otro aspecto constitutivo de los programas de perfeccionamiento es la suposición de que hay un algo que debe ser superado, llámese, por ejemplo, lo extraño, lo salvaje, la animalidad, la violencia, la locura, el pecado, la vejez, la mortalidad, la infancia, las pasiones, el deseo, la pobreza, la enfermedad y la debilidad. Esto por superar es fundamental porque hace las veces de contraimagen con la que se justifica y legitima ese ideal de formación.

Los ideales de formación se tornan en imaginarios culturales que se constituyen en referentes, aunque en muchas ocasiones no de manera racionalmente clara, para orientar el pensamiento, la acción y los sentimientos de las personas. Se instauran, sin embargo, a partir de relaciones de poder. En esas luchas se establecen las diferenciaciones y, paralelamente, se imponen tales ideales como aspectos, en muchos casos, esenciales y/o naturales.

En vista entonces de la indeterminabilidad de la formabilidad humana - de niños y niñas- y de la indeterminabilidad de un telos de la formación humana y de la historia (Benner, 1991, p. 22), lo que permanece como aceptable es mantener - dejarle al ser humano- el futuro abierto y no caer ni en pedagogías ni en humanismos normativos. Se da un doble no-saber: el de la naturaleza del ser humano y el de la determinación final de este; lo que señala la relación ambivalente de la pedagogía con el futuro y la situación de crisis de la praxis educativa.

\subsection{Aporía y crisis de la educación con relación a la animalitas vs. humanitas: ¿educación y/o eugenesia?}

A partir de Kant se hace visible la estrecha relación que hay entre antropología y pedagogía. De acuerdo con Kant, esa antropología, entendida ahora en sentido pragmático y no fisiológico, se pregunta por lo que el hombre, "como ser que obra libremente, hace, o puede y debe hacer, de sí mismo" (Kant, 1991, p. 7) ${ }^{20}$. Lo que lleva a proponer así una idea de estructuración epigenética del ser humano, según la

${ }^{19}$ Cf.: Kamper y Wulf, 1994, p. 10.

${ }^{20}$ Cf.: Kant, 1995, p. 399. 
cual este ya no se encuentra insoslayablemente determinado por su propio desarrollo natural, ni por su origen metafísico o religioso, sino por sus propias prácticas; es decir, por lo que hace de sí. En la antropología de Kant se concibe al hombre, a diferencia del animal, no como un ser determinado por el instinto, sino como un ser racional, o para ser más exactos, como un animal dotado de la capacidad de razón — "Vernunftfähigkeit begabtes Tier” (Kant, 1995, p. 673)— Según este mismo autor: "Un animal ya lo es todo mediante su instinto [...] Pero el hombre necesita razón propia. No tiene instinto y debe hacer de sí el plan de su comportamiento. Pero como no está inmediatamente en condición de hacerlo, sino que viene en bruto al mundo, entonces otros lo deben hacer por él” (Kant, 1995, p. 697). De acuerdo con esta visión, si se quiere mundana, el ser humano no solo es visto como un ser que fracasa en este mundo como animal desde su nacimiento, sino como un ser que se ha de entender a sí mismo como historia y, sobre todo, como proyecto por realizar, como un ser "excéntrico" (Plessner). Hablamos así de una animalidad bumana que no está determinada, como en el caso de los animales, por el instinto, sino que se trata de una animalidad abierta, formable, perfectible y libre, sujeta al plan que pueda dársele o darle a su propio comportamiento. Es en este contexto que los seres humanos empiezan a entenderse a sí mismos como seres flexibles, maleables, formables. De allí, igualmente, que la educación se conciba como el medio más apropiado para que este animal dotado de razón — animal rationabile - haga de sí mismo un animal racional —animal rationale — ${ }^{21}$. Podría uno decir que no es fortuito ni accidental que el mismo Kant diga por ello que: “detrás de la educación se encuentra el gran secreto del perfeccionamiento de la naturaleza humana" (Kant, 1995, p. 700). Bajo las coordenadas modernas se inaugura ese paradigma del perfeccionamiento humano que, si bien tiene todavía como presupuestos antropológicos las ideas de ser humano como creación divina o como ser dotado de razón, sienta las bases para una concepción de perfeccionamiento transhumano en el que incluso se trata de dejar ya de lado la misma "naturaleza humana"22.

En esa lógica, si el ser humano es un ser que es tarea de sí mismo y, en un cierto momento, de los otros, entonces también se presupone con ello, por principio, que dicho ser es formable (bildsam) y necesitado de educación (erziehungsbedürftig). Lo interesante de todo esto es que con esa concepción de una antropología en sentido pragmático la educación adquiere una fundamentación antropológica. En ese sentido, y el mismo Kant lo escribe: "El hombre es la única criatura que tiene que ser educada [...] El hombre solo puede volverse hombre mediante la educación. Él no es más que lo que la educación hace de él” (Kant, 1995, p. 697-699). De allí que la educación, entendida en su sentido amplio como cuidado (Wartung), disciplina (Disziplin), instrucción (Unterweisung) y formación (Bildung) ${ }^{23}$, tenga como tarea

\footnotetext{
${ }^{21}$ Cf.: Kant, 1995, p. 673.

${ }^{22}$ Cf.: Wulf y Zirfas, 2008, p. 9.

${ }^{23}$ Cf.: Kant, 1995, p. 697.
} 
fundamental evitar la posible caída en el salvajismo y la animalidad del individuo — del niño- e introducirlo, en cambio, en el camino de la razón — de la racionalidad- para que este logre así su autonomía.

Independientemente de su fundamentación antropológica, la educación se torna paradójica ya que para el pensamiento pedagógico y también antropológico — tal como lo expresa Kant - se es libre si uno se deja educar; pero, de igual manera, se es autónomo (mündig), se tiene razón propia, solo si se es libre. Lo paradójico resulta entonces cuando uno se percata de que en ese marco de reflexión la educación, con la que se le ayuda al otro a realizar su libertad, es también un influjo sobre él; por tanto, si uno se deja educar, renuncia con ello a la propia libertad. En ese sentido, el fin y propósito de la educación es precisamente aquello que ella misma hace imposible, aquello que ella desmiente. Esto lo había expresado también el mismo Kant cuando se preguntaba en su "Pedagogía": “¡cómo cultivo la libertad mediante la coacción?" (Kant, 1995, p. 711). Como lo dice Wimmer: "En esa antinomia de la pedagogía moderna en la que la posibilidad de educación es desmentida por la determinación de su destinatario que es representado como libre, o mejor, que tiene que ser supuesto como tal, se muestra la paradoja insoluble que surge mediante el descubrimiento del otro para la pedagogía” (Wimmer, 1994, p. 120).

La manera en que el pensamiento pedagógico moderno pro-kantiano ha tratado de liberarse de tal paradoja constitutiva es recurriendo a la moralización de la propia intención pedagógica. En tal proceso, si se resuelve el autoimpedimento que el mismo pensamiento pedagógico ha construido, es porque se vincula por necesidad los fundamentos de la actividad educativa y las técnicas de su realización a una idea del bien que solo puede ser una referencia al deber $\operatorname{ser}^{24}$. Por eso, siguiendo a Kant, "los niños deben ser educados en adecuación no con el estado presente, sino con el estado futuro y mejor posible del género humano; esto es: según la idea de humanidad" (Kant, 1995, p. 704). La reflexión pedagógica comienza a vivir así de su imaginación, de sus ideales formativos y, consecuentemente, del incumplimiento real de sus intenciones — esto porque no sobra recordar acá que los ideales son para este autor ideas de una perfección que como tal no se puede realizar o cumplir, pero que hay que tener como útiles para orientar el pensamiento y la acción ${ }^{25}-$. De allí que el proyecto para una teoría de la educación, es decir, el fin formativo último, aparezca como un "ideal noble y no dañe en nada si aún no estamos en situación de realizarlo" (Kant, 1995, p. 700) y que, en resumidas cuentas y si se lo mira bien, "la educación sea el problema más grande y más difícil que se le pueda dar al hombre" (Kant, 1995, p. 702). Con ello la construcción o formación de teorías pedagógicas se vuelve progresivamente improbable y pierde el contacto con la realidad (Oelkers, 1983, p. 813). Precisamente por ello se vuelve exitosa, pues se puede esperar lo que sea de

\footnotetext{
${ }^{24}$ Cf.: Corsi, 2002, p. 29.

${ }^{25}$ En palabras de Kant, "una idea no es otra cosa que el concepto de una perfección que todavía no se encuentra en la experiencia" (Kant, 1995, p. 700-701).
} 
la respectiva educación futura. Como lo sostiene Sloterdijk: "Se halla en juego aquí nada menos que una antropodicea, es decir, una determinación del ser humano de cara a su apertura biológica y a su ambivalencia moral. Pero, por sobre todo, está la pregunta por cómo podría entonces el ser humano convertirse en un ser humano verdadero o real, que a partir de ahora será formulada inevitablemente como una pregunta por los medios, si por estos entendemos los medios comulgales y comunicativos, por medio de cuyo uso los humanos mismos se forman para aquello que pueden ser y llegar a ser" (Sloterdijk, 1999, p. 19).

Así pues, con esa idea de perfeccionamiento (Perfektionierung) no solo se alude a esa apertura biológica en la que la antropología kantiana deja al ser humano, sino también a ese mundo de los ideales de formación que, como ideas de una perfección, tan solo son imaginables. Inmejorabilidad y perfeccionamiento humano marcan así los límites de una "naturaleza humana" que, por un lado, se entiende como potencia y capacidad para la superación de las limitaciones naturales y, por el otro, como instancia de optimización, de maximización de la productividad, de uso eficiente (biopoder).

Otro asunto interesante que resulta de ese gran impensado de la domesticación humana bajo las coordenadas de la modernidad es que si el hombre, en tanto humanitas, es por lo que hace de sí, entonces su bumanitas no resulta ser más que bestialidad bajo influjo. Una bestialidad des y reacostumbrada por el influjo de la educación y de las prescripciones de la razón. La autonomía aparece en este contexto como coacción y autocoacción progresivas e intensificadas. De allí precisamente la importancia de la disciplina (Disziplin, Zucht), pues esta, sobre todo, es la que "transforma la animalidad en humanidad [...] La disciplina previene que el hombre, a causa de sus impulsos animales, se desvíe de su determinación, de la humanidad [...] El salvajismo ( Wildheit) es la independencia de las leyes. La disciplina somete al hombre a las leyes de la humanidad y comienza a hacerle sentir la obligación de estas [...] De allí que el hombre tenga que acostumbrarse desde temprano a someterse a las prescripciones de la razón” (Kant, 1995, p. 697-698). Frente a la radical separación entre el reino de la naturaleza y el reino de los fines, la humanitas pone en tensión dicha separación kantiana, ya que esta no resulta ser más que "bestialidad libre" y abierta sujeta a encauzamiento, a autoencauzamiento, a docilización. Pero continuemos con Kant: "No obstante, el hombre tiene por naturaleza una gran inclinación (Hang) por la libertad, que, cuando durante un cierto tiempo se acostumbra a ella, lo sacrifica todo a ella [...] En los hombres, por su inclinación hacia la libertad, es necesario un pulimiento (Abschleifung) de su estado en bruto (Rohigkeit); en los animales, por el contrario, no lo es, debido a sus instintos" (Kant, 1995, p. 698-699). De allí nuevamente la importancia que cobra de la pregunta por los medios adecuados y correctos - legítimos - para influir sobre esa animalitas, para acostumbrarla, para pulirla, para optimizarla, para funcionalizarla, para hacerla rendidora.

De todas maneras, lo que más llama la atención del planteamiento antropológico kantiano anterior para nuestros propósitos es que como no se sabe con certeza hasta dónde va lo fisiológico y en dónde comienza lo pragmático — lo cultural—, entonces 
toda determinación del ser humano de ahora en adelante no puede más que moverse dentro de una ambigüedad fundamental: la determinación del ser humano queda signada como indeterminabilidad: el ser humano como un "nicht festgestelltes Tier" (Nietzsche). La determinación del lugar especial que ocupa el ser humano dentro de los seres vivientes no se da ahora ni en delimitación de lo animal, ni en delimitación con la máquina, ni en delimitación con Dios. De allí que lo que el ser humano fue, es o pueda ser, está marcado por una “diferencia antropológica” (Kamper) que consiste en que el ser humano como ser identificante no puede ser identificado o identificarse sino al costo de su imperfecta cosificación. El ser humano en tanto ser formable, abierto y perfectible solo llega a puerto seguro mediante definiciones de sí que nunca logran ser definitivas. Desde esta mirada, el ser humano es el único ser que para existir en el mundo tiene que dar permanentemente definiciones de sí, así estas sean solo provisionales. Esto quiere decir, como lo plantea Bollnow desde una antropología pedagógica, que "la [...] esencia del ser humano permanece por principio infundamentable, con lo que se tiene que tomar el concepto de infundamentabilidad (Unergründlichkeit) en un sentido estricto. Este no solo significa que con nuestros esfuerzos nunca vamos a avanzar hacia un fundamento último, sino que la vida humana no tiene ningún fundamento y es una fuente de la que resultan nuevas posibilidades increadas en el proceso creador. La apreciación sobre la infundamentabilidad no significa, en el sentido de un irracionalismo primitivo, que todo intento de determinación conceptual sería, desde un principio, carente de sentido o enemigo de la vida. Aquella exige, más bien, impulsar hasta los límites externos de lo posible el esfuerzo en torno a una comprensión mental; así, con ese esfuerzo se acrecienta y asciende la vida misma [...] Pero sabe, igualmente, que toda afirmación que apunte hacia algo se encuentra ligada a aspectos particulares a partir de los cuales no se comprende la vida en su totalidad, y que detrás de todo resultado así logrado permanece la oscuridad de lo no esclarecido (Bollnow en: König y Ramsenthaler, 1980, p. 51). Esta era de cierto modo también la idea de Werner Loch cuando planteaba en un artículo de 1965 que con el concepto de ser humano el concepto de educación se había convertido forzosamente en una 'pregunta abierta' que - como consecuencia de la variabilidad (Veränderlichkeit) histórica del ser humano- siempre tenía que ser respondida de una manera nueva y como consecuencia de ello, tampoco podía llegar a ser respondida de una manera concluyente, mientras el ser humano estuviera sometido al principio de variabilidad.

Lo anterior significa, desde otro punto de vista, que el pensar sobre el ser humano, gracias a la reflexión permanente, se debe defender de sí mismo mediante una especie de permanente "Aufhebung" — en el sentido hegeliano_ en la que la conditio humana siempre aparece fluctuando entre naturaleza y cultura sin ser ni la una ni la otra. Según los planteamientos antropológicos de Kant, el ser humano pertenece a ambos mundos — es ciudadano de dos mundos- y su "naturaleza" es por ello un compuesto no diferenciable. De allí entonces que la educación —que es la que acá nos interesa-, vista según esa concepción antropológica, también se tenga que mover, sin definirse nunca, 
dentro de esas dos alternativas posibles, a saber: como desarrollo y como cultivo ${ }^{26}$, en la medida en que ella, en parte, algo le enseña al ser humano y, en parte, algo le desarrolla. Citemos nuevamente Kant: "Pero, debido a que la educación en parte algo le enseña al hombre y en parte también solo en él algo le desarrolla, entonces no se puede saber qué tan lejos van en él las disposiciones naturales" (Kant, 1995, p. 699). Y esto nos recuerda, como dijimos al comienzo, lo más escandaloso suscitado por las "Reglas para el parque humano", a saber: que allí Sloterdijk subsumiera bajo el neologismo "antropotécnica" toda una serie de prácticas y procesos humanizadores —educación, formación, socialización, culturización, etc.— que siempre habíamos tenido por algo diferenciado y que, bajo estas coordenadas modernas, parecen ya no tener unos límites los suficientemente claros que nos permitan distinguir - moralmente hablando- entre prácticas eugenésicas y prácticas educativas. De fondo aparece entonces esa contingencia antropológica que se busca dominar mediante diferentes medios y que se hace más problemática con la entrada en el "siglo de la infancia" (Key).

Ahora bien, si con estos influjos domesticadores de las tendencias bestializantes no se sabe si se enseña o desarrolla algo, en el sentido kantiano, entonces tampoco se puede saber si, en sentido estricto, se trata de educación o eugenesia. El resultado es una "antropotécnica real [que] exige entonces del hombre de estado que entienda cómo entrelazar entre sí para el común (Gemeinwesen), y de la manera más efectiva, las características propicias de hombres dóciles por libre voluntad, de modo que bajo su dirección, el Parque Humano alcance una homeostasis óptima. Esto ocurre si ambos óptimos relativos a la especie humana, la osadía guerrera por un lado, y la sensatez filosófico-humana, por el otro, llegan a entramarse equilibradamente en el tejido de lo común" (Sloterdijk, 1999, p. 52-53). En el contexto de una época de la "gubernamentalidad" (Foucault) marcada por el ejercicio de un "biopoder" este impensado de la domesticación humana comienza a resolverse a través de medios que ya no son claramente diferenciados. La vida aparece como objeto de atención para unos propósitos mejoradores. Así, de "manera simétrica, la vida en sentido biológico ingresa acabadamente en los juegos del poder: la vida constituye la materia de la ciencia y de la práctica del derecho, se convierte en el centro de imputación de los procesos y actos administrativos a todo nivel, es el nombre que sintetiza las fuerzas productivas del capital y finalmente el objeto que está implicado en todos los objetivos de la política. La diferencia sustancial entre la biopolítica moderna y la de otrora es que mientras antes la vida era asumida como un dato sustancialmente invariable, desarrollado sobre la base de leyes propias que la política, la economía, el derecho, la administración podían modificar solo formalmente, en el siglo XX la vida se convierte en una realidad esencialmente indeterminada y, por lo tanto, potencialmente manipulable y acaso hasta reproducible" (Pandolfi, 2006, p. 190). La vida, pero específicamente la aparente contingencia antropológica, se vuelve en el objeto de una serie de intervenciones intencionadas que, por un lado, se ve como amenaza de la "naturaleza humana" y, por el otro, como la posibilidad de un nuevo ser humano, de un perfeccionamiento posthumano.

\footnotetext{
${ }^{26}$ No sobra remitir acá a la etimología de esta última palabra y su extendido uso metafórico.
} 


\section{Conclusiones: la nueva concepción del ser humano y las aporías de la pedagogía moderna}

Recordemos que, a manera de ejemplos representativos, vimos con Kant el problema de legitimación de la educación bajo el presupuesto de un sujeto libre que se autodetermina - antropología en sentido pragmático- Con Rousseau vimos el problema de legitimación de la educación y de sus fines en relación con una concepción ateleológica de la perfectibilidad (perfectibilité) y con una concepción del niño como otredad natural indeterminada. Nuevamente con Kant visibilizamos la situación problemática de desdiferenciación de la educación como cultivo o como desarrollo y sus nuevas connotaciones como antropotécnica eugenésica. Gracias a estas condiciones surgidas de la modernidad y presentadas a partir de los autores anteriores, toma forma una concepción del ser humano sin precedentes en la que se parte de la diferenciación de este frente a los demás seres, debido, fundamentalmente, a su racionalidad, su libertad, su formabilidad — maleabilidad, plasticidad-y su capacidad de perfeccionarse. En tanto ser pensante y libre (voluntad libre), el ser humano moderno empieza a verse a sí mismo como un ser mejorable y, sobre todo, señor, dueño y responsable de su propio destino. Lo característico de la condición del ser humano moderno como un ser que llega al —que es arrojado (Heidegger) en el- mundo para hacerse, para formarse, para hacer su historia propia es que con ello también se le da justificación a una serie de estrategias e intervenciones que se implementan precisamente en nombre de unos ideales de formación por alcanzar y de una naturaleza por desarrollar. Se abre así el paradigma del perfeccionamiento humano en el que la praxis educativa queda concebida en el marco de unos de presupuestos paradójicos que evidencian su permanente tensión.

En ese contexto y proyectado hacia el futuro, el sueño de la pedagogía moderna se convierte, a la vez, en una suerte de pesadilla permanente y real, que consiste en esa obsesión constante por llegar a un estado de perfección, a un estado óptimo y conseguir así "lo mejor". La educación, en el contexto de unas formas modernas de biopoder, penetra así lo que se considera natural —naturaleza indeterminada, maleable, formable- para procurar su buen encauzamiento y mejoramiento. En ese sentido, la pedagogía moderna se instaura como la garante del futuro abierto del niño y en ello justifica su hacer y su reflexionar, en otras palabras, su existencia; pero con ello se evidencia también su paradójica situación: no saber lo suficiente del niño ahora — de su naturaleza indeterminada - no poder prever con seguridad su —realización en el- futuro ${ }^{27}$, ni poder legitimar y justificar con certeza sus formas de intervención —educaciónLa intención de una renovación absoluta —en la educación- solo se hace posible de

\footnotetext{
27 "Se ha dicho que la educación es un arte. Ciertamente lo es —arte grandioso que tiene por objeto preparar para la vida - más se olvida a menudo que aquí la materia prima no es materia muerta como en las otras artes: no es piedra, no es madera, no es lienzo [... A Aquí la materia vive, es materia pensante, es el niño, es el hombre. Esto significa que el artista —el maestro — no puede, no debe, dominarla por completo. Hay que respetar en ella su propia esencia: estudiarla para desentrañar lo bello que contenga, para colaborar con ella, modelándola sin violentarla, sin quebrarla jamás" (Nieto Caballero, 1915, p. 343-344).
}

[129] Revista Colombiana de Educación, N. ${ }^{\circ}$ 59. Segundo semestre de 2010, Bogotá, Colombia. 
una manera violenta y totalitaria, y mediante un control total y una educación y una formación limitadas — restringidas- También, aparece la tensión entre las pretensiones normativas de un exigido perfeccionamiento y las exigencias y presiones para su realización. La exigencia de constatar, medir, palpar, ver, corroborar una perfección realizada aqui y ahora, es decir, una formabilidad restringida.

La praxis pedagógica — la labor pedagógica- no puede prometer o generar un progreso hacia un estado mejor. Esto se ratifica por el hecho mismo de que la educación no es una tecnología - déficit tecnológico de Luhmann- por medio de la cual se pudieran controlar las secuencias interactivas sin efectos secundarios negativos y sin atender, en el sentido de la teoría neo-sistémica de Luhmann- a la doble contingencia. Escepticismo en cuestiones normativas porque la diferencia entre presente y futuro no solo apoya y fundamenta las exigencias de educación — la necesidad de la educación-, sino que contribuye a mantener abierta esa diferencia. Formabilidad humana e indeterminabilidad — perfectibilidad - humana fundamentan antropológicamente la estructura básica de la conditio humana moderna, con la cual la educación se vuelve —antropológica, social, cultural e históricamente- necesaria, pero, a su vez, imposible - en el sentido de su realización plena-.

En conclusión, la crisis de la sociedad moderna occidental evidencia la posibilidad histórica de pensar otras alternativas civilizatorias, otras formas de estar y ser en el mundo. Consecuente con ello, la pedagogía en una lectura posmoderna deberá reconocer diferentes dinámicas o procesos de subjetivación que parten de múltiples ideales del ser humano. Así, la educación y la formación no serán dogmatismos sino reconocimiento de alteridades. Así, la alteridad como reconocimiento de los rostros de lo otro y los otros en mí, se refiere a la incapacidad de distanciarme. Con Schleiermacher se plantea la idea de una relación pedagógica intergeneracional en la que los adultos ya no son los representantes de un orden tradicional que saben del futuro de los jóvenes, ni menos anticipan dicho futuro en representación de estos, sino que promueven en ellos, con medidas de apoyo y neutralización, determinados procesos de aprendizaje que les preparan para intervenir en una discusión, que ha de hacerse pública, sobre lo que conviene mantener y lo que se debe cambiar. Nos las habemos con la idea de una praxis educativa y una formación no afirmativas que inciten a la autoactividad y la toma de decisiones en el contexto de diferentes mundos posibles. En ese sentido, el agotamiento de energías utópicas en la sociedad del riesgo permite reavivar la pregunta por los mundos posibles, y la concreción en los sujetos de formas de ser con base a un conocimiento y cuidado de sí. Escepticismo pedagógico de cara a una utopia realizable y ampliación de horizontes de cara a una formación no afirmativa. 


\section{Referencias bibliográficas}

Adorno, T, W. (1975). Dialéctica negativa. Madrid: Cuadernos para el Diálogo.

Badinter, E. (1980). L'amour en plus. Histoire de l'amour maternel du XVII ${ }^{\circ}$ an $X X^{\circ}$ siècles. Paris: Flamarion.

Bauman, Z. (2005). La sociedad sitiada. México: Fondo de Cultura Económica.

Beck, U. (1998). La sociedad del riesgo, hacia una nueva modernidad. Barcelona: Editorial Paidós.

Benner, D. (1991). La capacidad formativa y la determinación del ser humano. Educación, vol. 43, p. 87-102.

- (1998). La pedagogía como ciencia. Teoría reflexiva de la acción y reforma de la praxis. Barcelona: Ediciones Pomares-Corredor.

Beriain, J. (1990). Representaciones colectivas y proyecto de modernidad. Barcelona: Editorial Anthropos.

Bollnow, O. F. (1980). Die anthropologische Betrachtungsweise in der Pädagogik, en König Eckard y Ramsenthaler Horst (eds.). Diskussion Pädagogische Anthropologie. München: Wilhelm Fink Verlag, p. 36-54.

Corsi, G. (2002). Sistemas que aprenden. Estudio sobre la idea de reforma en el sistema de educación. México: Universidad Iberoamericana.

Flitner, W. (1972). Manual de Pedagogía General. España: Editorial Herder.
Foucault, M. (2006). Defender la sociedad. México: Fondo de Cultura Económica.

Fullat, O. (1997). Antropología filosófica de la educación. Barcelona: Editorial Ariel Educación.

Giddens, A. (1995). Modernidad e identidad del yo. Barcelona: Ediciones Península.

Habermas, J. (1994). Ensayos políticos. Barcelona: Ediciones Península.

. (2000). Teoría y praxis. Madrid: Editorial Tecnos.

. (1935). Bosquejo para un curso de pedagogía. Madrid: Ediciones La Lectura, Espasa-Calpe. . (1984). Umriss pädagogischer Vorlesungen, Tomo 1. Revisada por J. Esterhues. Paderborn: Schöningh. . (1986). Systematische Pädagogik. Introducida, escogida e interpretada por D. Benner. Stuttgart: Klett-Cotta.

Horkeheimer, M. \& Adorno, T. (1994). Dialéctica de la Ilustración. Madrid: Editorial Trotta.

Kamper, D. \& Wulf, C. (eds.) (1994). Vervollkommnung und Unverbesserlichkeit. Anthropologie nach dem Tod des Menschen. Frankfurt am Main: Suhrkamp Verlag.

Kant, I. (1983). Pedagogía. Madrid: Akal. 
- (1991). Antropología en sentido pragmático. Madrid: Alianza Editorial.

- (1995). Schriften zur Anthropologie, Geschichtsphilosophie, Politik und Pädagogik. Tomo 2. Frankfurt am Main: Suhrkamp Verlag.

König, E. \& Ramsenthaler, H. (eds.) (1980). Diskussion Pädagogische Anthropologie. München: Wilhelm Fink Verlag.

Luhmann, N. (1991). Sistemas sociales. Madrid: Alianza Editorial. - (1996). Teoría de la sociedad y pedagogía. Barcelona: Editorial Paidós.

Nieto, A. (1915). La escuela normal de institutores, en Cultura, vol. I, núm. 5, Bogotá, p. 340-278.

Oelkers, J. (1997). Erziehung als Vollendung. Kritische Überlegungen zu einem pädagogischen Ideal, in: Christoph Lüth und Christoph Wulf (eds.). Vervollkommnung durch Arbeit und Bildung? Anthropologische und historische Perspektiven zum Verhältnis von Individuum, Gesellschaft und Staat. Weinheim: Belt, Deutsche Studien Verlag, p. 13-51.

Pandolfi, A. (2006). Naturaleza bumana. Léxico de política. Buenos Aires: Ediciones Nueva Visión.

Rousseau, J. Ouevres complètes I-V. Éd. Gagnebin, B. y Raymond, M. Bibliothèque de la Pléiade, Paris, Gallimard, 1959 $-1995,5$. Vols. (O.C).
Rousseau, J. (1980). Del contrato social. Discurso sobre las ciencias y las artes. Discurso sobre el origen de la desigualdad entre los hombres. Prólogo, traducción y notas de M. Armiño. Madrid: Alianza Editorial. - (1998). Emilio, o De la educación. Prólogo, traducción y notas de M. Armiño. Madrid: Alianza Editorial.

Runge, A. K. (1999). La paradoja del re-conocimiento de la niñez desde la pedagogía. Reflexiones en torno al eco rousseauniano, en: Revista Educación y Pedagogía, núm. 23-24 (Enero-Agosto). . (2008). Ensayos sobre pedagogía alemana. Bogotá: Universidad Pedagógica Nacional. . (2010). La ciencia de la educación como profesión en Alemania En: Saenz, Javier (ed.) (2010). Pedagogía, saber y ciencias. Bogotá: Universidad Nacional, Universidad de Antioquia. - Breve introducción al campo disciplinar y profesional de la pedagogía. Consideraciones básicas sobre pedagogía, práctica educativa y saber pedagógico. (Mimeo).

Klaus, A. \& Garcés, J. F. (2006). Reflexiones pedagógicas sobre la relación entre universidad, docencia y formación en una perspectiva histórica. Medellín: Universidad de Antioquia.

Klaus, A. \& Muñoz, D. (2005). Educación, formación, pedagogía y crisis de la modernidad: la reivindicación del ser humano como ser crísico. En: Arellanos Duque, A. (coord.). La educación en 
tiempos débiles e inciertos. Barcelona: Anthropos Editorial; Bogotá: Convenio Andrés Bello, p. 343-376.

Schleiermacher, F. E. D. (2000). Texte zur Pädagogik. 2 vols. Editada por M. Winkler y J. Brachmann. Frankfurt am Main: Suhrkamp Verlag.

Sloterdijk, P. (1999). Regeln für den Menschenpark. Ein Antwortschreiben zu Heideggers Brief über den Humanismus. Frankfurt am Main: Suhrkamp Verlag.

Wimmer, M. (1994). Die Frage des Anderen, en Wulf, Christoph (ed.) (1994). Einfübrung in die pädagogische Anthropologie. Weineheim und Basel: Beltz Verlag.

Wulf, C. (ed.) (1994). Einführung in die pädagogische Anthropologie. Weinheim und Basel: Beltz Verlag.
- (2000). Introducción a la

ciencia de la educación, entre teoría y práctica. Medellín: Asonen y Facultad de Educación Universidad de Antioquia. - (2004). Antropología de la educación. Barcelona: Idea Books Educación.

. \& Zirfas, J. (2008). Lebensdiskurse. Eine Einleitung, en: Paragrana, vol. 2, núm. 17, p. 9-12. . \& Zirfas, J. (eds.) (1994). Theorien und Konzepte der pädagogischen Anthropologie. Donauwörth: Ludwig Auer BmgH.

Zirfas, J. (1993). Präsenz und Ewigkeit. Eine Anthropologie des Glücks. Berlin: D. Reimer. 